\title{
Boron removal and desalination from seawater by PVDF flat-sheet membrane through direct contact membrane distillation
}

\author{
Deyin Hou ${ }^{\text {a,* }}$, Guohua Dai ${ }^{\mathrm{b}}$, Jun Wang a,*, Hua Fan ${ }^{\mathrm{c}}$, Zhaokun Luan ${ }^{\mathrm{a}}$, Chaochen Fu ${ }^{\mathrm{d}}$ \\ a State Key Laboratory of Environmental Aquatic Chemistry, Research Center for Eco-Environmental Sciences, Chinese Academy of Sciences, P.O. Box 2871, Beijing 100085, China \\ b State Key Joint Laboratory of Environment Simulation and Pollution Control, POPs Research Center, School of Environment, Tsinghua University, Beijing 100084, China \\ c School of Environmental and Chemical Engineering, Nanchang University, Jiangxi 330031, China \\ d Beijing Water Authority, Beijing 100038, China
}

\section{H I G H L I G H T S}

- PVDF flat-sheet membrane was prepared for boron removal and desalination.

- The membrane had a narrow pore size distribution and exhibited good hydrophobicity.

- Simultaneous boron removal and desalination from real seawater was carried out.

- The influence of antiscalant on boron removal and desalination was investigated.

- The prepared membrane was efficient for boron removal and desalination by DCMD.

\section{A R T I C L E I N F O}

\section{Article history:}

Received 24 April 2013

Received in revised form 27 July 2013

Accepted 29 July 2013

Available online 22 August 2013

\section{Keywords:}

Membrane distillation

Boron removal

Desalination

Hydrophobic membrane

Antiscalant

\begin{abstract}
A B S T R A C T
Boron removal and desalination from seawater by direct contact membrane distillation (DCMD) was studied with self-prepared polyvinylidene fluoride (PVDF) flat-sheet membrane. The membrane had an ultra-thin top skin and a porous network sponge-like layer and its effective pores showed a narrow distribution with a mean pore size of $0.22 \mu \mathrm{m}$. The membrane exhibited good hydrophobicity and its contact angle was about $82.6 \pm 0.7^{\circ}$. During DCMD test of $35 \mathrm{~g} / \mathrm{L}$ sodium chloride solution, the maximum permeate flux can achieve $47.6 \mathrm{~kg} / \mathrm{m}^{2} \mathrm{~h}$. The natural seawater containing $4.65 \mathrm{mg} / \mathrm{L}$ boron was treated by DCMD for simultaneous boron removal and desalination. Although the permeate flux decreased with concentration factor (CF) value increase, the permeate boron kept below $20 \mu \mathrm{g} / \mathrm{L}$ and salt rejection was over 99.9\%. When the $\mathrm{CF}$ value exceeded 4.0 , there would be scale deposits formed, and the permeate quality and flux declined rapidly. The antiscalant polyacrylic acid could delay the deposit formation and the advisable dosage was $10 \mathrm{mg} / \mathrm{L}$. The membrane showed satisfying performance stability in a $300 \mathrm{~h}$ continuous DCMD experiment even with the CF value as high as 7.0, indicating that the selfprepared membrane and DCMD process could be efficiently used for boron removal and desalination from seawater.
\end{abstract}

(c) 2013 Elsevier B.V. All rights reserved.

\section{Introduction}

Boron is widely distributed in both the hydrosphere and lithosphere of the earth. Generally, boron in aqueous environment is found in the form of boric acid and partial borate salts [1]. Boron acts as one of the most important micronutrients for plants, and is essential for normal growth of most crops. However, there is a narrow range between its deficiency and toxicity; boron is beneficial to plants only in small quantities and excessive amounts are injurious and even lethal [2]. Long-term exposure to water with increased boron content can result in malfunctioning of cardiovascular, nervous, alimentary, and sexual systems of humans and animals [3-6].

\footnotetext{
* Corresponding author. Tel./fax: +86 1062849150

E-mail addresses: deyinhou@126.com, dyhou@rcees.ac.cn (D. Hou), junwang@rcees.ac.cn (J. Wang).
}

The World Health Organization (WHO) once set a guideline limit of $0.5 \mathrm{mg} / \mathrm{L}$ for boron in drinking water and the value is revised to $2.4 \mathrm{mg} / \mathrm{L}$ recently [7]. Although this new change seems more relaxed for drinking water, the requirement of $0.5 \mathrm{mg} / \mathrm{L}$ is still kept for irrigation water since boron demonstrates herbicidal effect [8]. In the European Union, a standard for boron in drinking water was $1.0 \mathrm{mg} / \mathrm{L}$; the standard for boron in drinking water at $0.5 \mathrm{mg} / \mathrm{L}$ was adopted in China. Due to increasing demand for water, both for potable use and for irrigation, coupled with a decrease in suitable water sources, seawater desalination has become more and more attractive. Boron exists in seawater at around 4-6 mg/L [9]; it is therefore important to control the boron level in the treated effluent for different applications.

Nowadays, reverse osmosis (RO) desalination has become more dominant as traditional thermal desalination technologies such as multiple effect distillation (MED), multi-stage flash distillation (MSF) and vapor compression (VC) lose favor on energy grounds. The RO 
technology showed excellent salt rejection but insufficient boron removal. This can be attributed to the chemistry of boron, at normal $\mathrm{pH}$ of operation of RO desalination plants; boron is mainly in the form of boric acid, which is uncharged and can diffuse through the RO membrane easily [10]. For most RO desalination plants, boron removal from seawater is becoming a challenging problem.

The existent accepted methods for boron removal from water are mainly adsorption, ion exchange, and membrane process. These technologies generally have certain limitations, especially for boron removal from saline water. Adsorption process can remove boron to a safe concentration and the treatment is cost-effective [11]. However, the boron removal efficiency is greatly affected by temperature, $\mathrm{pH}$ and properties of adsorbent [12]. Besides, this method requires a regeneration process after the adsorbents being exhausted, which may decrease the capacity of adsorbents and produce secondary pollution. As the most efficient method, ion-exchange process can even remove boron to levels of $<50 \mu \mathrm{g} / \mathrm{L}$, far below the required limits [13]. Although the performance of boron specific ion exchange resin cannot be affected by temperature or $\mathrm{pH}$ value variations of the water to be treated [14], the process is usually not feasible under high background salinity [15]. RO membrane process is the simplest method for reducing boron concentration from seawater associated with the reduction of salinity and it is also expected to have great potential [16]. The main drawback of this method is the need of multi-pass RO systems to reduce boron concentration to the current recommended level, which causes the increase in costs. In addition, elevated $\mathrm{pH}$ for boron removal would lead to scaling, corrosion and higher cost [17].

Membrane distillation (MD) is an emerging thermally driven membrane separation technology that involves transport of water vapor through a porous hydrophobic membrane [18]. During the MD process of solutions with non-volatile solutes, only water vapor can transfer through the membrane. It may be used as a substitute for conventional separation processes such as multistage vacuum evaporation, distillation and RO [19]. Compared with those processes, the advantages of MD are as follows: (1) lower operating temperature and less vapor space required than conventional distillation, (2) lower operating pressure than RO, (3) 100\% (theoretical) rejection of non-volatile solute, (4) unlimited by high osmotic pressure and (5) lower energy consumption than multistage vacuum evaporation $[20,21]$. So far the MD technology has been applied for water desalination [22], waste water reuse [23], juice concentration processing [24] and other industrial areas [25-27]. Although many researchers have been working on seawater desalination by $\mathrm{MD}$, most works focus on the MD membrane and module development [28-30], operation conditions investigation and optimization [31,32], novel MD hybrid process [33,34], and heat and mass transfer theory [35-37]. As far as we know, studies related to the simultaneous desalination and boron removal through MD process are rather limited.

Direct contact membrane distillation (DCMD) is the best known configuration of MD and is also considered to be the most simple in
Table 1

Chemical composition of the untreated seawater.

\begin{tabular}{lrlr}
\hline Constituent & Content & Constituent & \multicolumn{1}{c}{ Content } \\
\hline $\mathrm{pH}$ & 7.90 & $\mathrm{TOC}(\mathrm{mg} / \mathrm{L})$ & 2.73 \\
Turbidity $(\mathrm{NTU})$ & 5.86 & Conductivity $(\mu \mathrm{S} / \mathrm{cm})$ & 43,600 \\
$\mathrm{~K}^{+}(\mathrm{mg} / \mathrm{L})$ & 405.84 & $\mathrm{~B}(\mathrm{mg} / \mathrm{L})$ & 4.65 \\
$\mathrm{Ca}^{2+}(\mathrm{mg} / \mathrm{L})$ & 383.33 & $\mathrm{~F}^{-}(\mathrm{mg} / \mathrm{L})$ & 3.30 \\
$\mathrm{Na}^{+}(\mathrm{mg} / \mathrm{L})$ & 9048.75 & $\mathrm{Cl}^{-}(\mathrm{mg} / \mathrm{L})$ & $18,669.70$ \\
$\mathrm{Mg}^{2+}(\mathrm{mg} / \mathrm{L})$ & 1186.97 & $\mathrm{Br}^{-}(\mathrm{mg} / \mathrm{L})$ & 67.93 \\
$\mathrm{Sr}^{2+}(\mathrm{mg} / \mathrm{L})$ & 7.39 & $\mathrm{HCO}_{3}^{-}(\mathrm{mg} / \mathrm{L})$ & 179.21 \\
$\mathrm{Si}(\mathrm{mg} / \mathrm{L})$ & 4.36 & $\mathrm{SO}_{4}^{2-}(\mathrm{mg} / \mathrm{L})$ & 2105.75 \\
\hline
\end{tabular}

design and application, in which the feed and the distillate are directly separated by the hydrophobic membrane. In the present study, DCMD experiments were carried out for boron removal and desalination from seawater with self-prepared polyvinylidene fluoride (PVDF) flatsheet membrane. The self-prepared PVDF flat-sheet membrane contained a hydrophobic PVDF porous separation function layer and a hydrophilic nonwoven fabric support layer, and its properties were characterized via scanning electron microscopy (SEM), an atomic force microscope (AFM), a capillary flow porometer (CFP) and contact angle measurement. The batch DCMD experiments were conducted for simultaneous boron removal and desalination from seawater at different concentration factor (CF) values and the effects of antiscalant polyacrylic acid (PAA) on mitigating the potential for membrane scaling were also investigated.

\section{Materials and methods}

\subsection{Materials}

PVDF (FR-904, Mw $=1.02 \times 10^{6} \mathrm{~g} / \mathrm{mol}$ ) was obtained from Shanghai 3F new materials Co., Ltd. (China). N,N-Dimethylacetamide (DMAc, >99\%) was employed as the solvent, purchased from Shanghai Jingwei Chemical Co., Ltd. (China). Acetone (AR grade, $>99.5 \%$ ) and phosphoric acid (AR grade, $>85.0 \%$ ) were supplied by Sinopharm Chemical Reagent Co., Ltd. (China). Ethanol (GR grade, 99.9\%) and $\mathrm{NaCl}$ (99.5\%) were from Beijing Chemical Works (China). Polyacrylic acid (PAA) was supplied by Zouping Dongfang Chemical Industry Co., Ltd. (China). The ultrapure water used in all experiments was produced by a Milli-Q BIOCEL unit (Millipore, USA) with the resistivity of $18 \mathrm{M} \Omega \cdot \mathrm{cm}$.

\subsection{Membrane preparation}

First, a desired amount of dried PVDF powder was poured into a tank containing DMAc solvent and non-solvent additives, then the polymer dope mixture was subjected to continuous stirring for about $48 \mathrm{~h}$ at

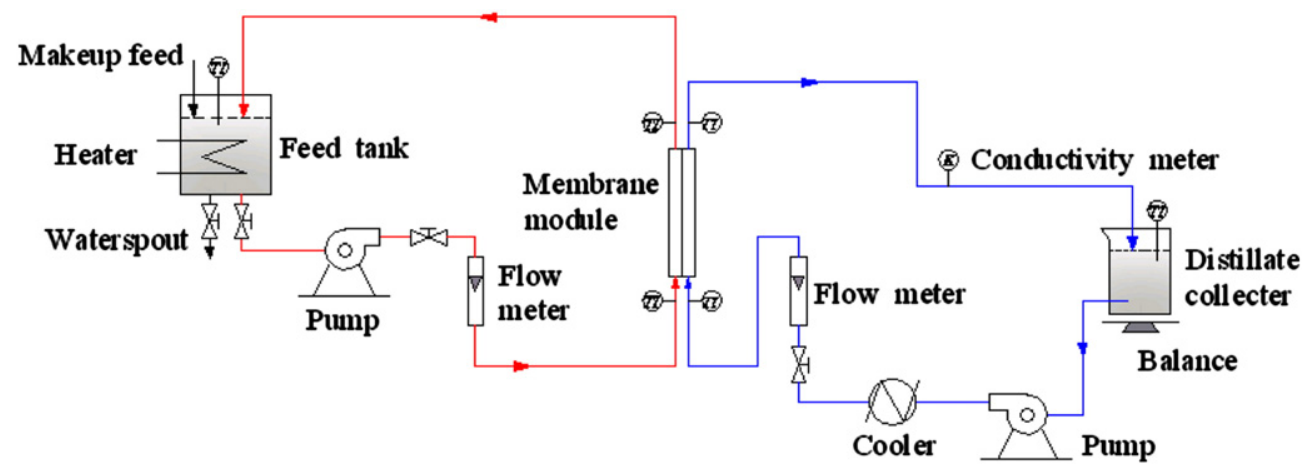

Fig. 1. Schematic diagram of the experimental DCMD set-up. 
$50{ }^{\circ} \mathrm{C}$ in order to ensure its homogeneity. Afterwards, the stirring was stopped and released the gas bubbles in the dope at $50{ }^{\circ} \mathrm{C}$ for about $72 \mathrm{~h}$. In this work, the mixture of acetone and $\mathrm{H}_{3} \mathrm{PO}_{4}$ was chosen as non-solvent additive and the dope solution contained 20 wt.\% PVDF, 72 wt.\% DMAc, 5 wt.\% acetone and 3 wt.\% $\mathrm{H}_{3} \mathrm{PO}_{4}$.

The degassed dope solution was cast on a polyester nonwoven fabric at room temperature with a knife gap of $0.2 \mathrm{~mm}$. After exposure for $30 \mathrm{~s}$ in air, the cast film was immersed immediately into an ultrapure water bath at $25{ }^{\circ} \mathrm{C}$. The precipitated membrane was removed from the coagulation bath and rinsed with running water to remove the residual solvent and additives. At last, the wetting membrane was dried in air at room temperature until to receive a dry flat-sheet membrane.

\subsection{Membrane characterization}

The morphology of membrane was investigated with a HITACHI S3000N scanning electron microscope (SEM) (Hitachi Ltd., Japan). Membrane sample was frozen in liquid nitrogen, fractured to obtain fragments, and sputtered with gold using a HITACHI E-1010 Ion Sputtering device for SEM observation.

An atomic force microscope (AFM) (NanoScope IIla, Digital Instruments, USA) was employed to analyze the surface state of the flatsheet membrane. The membrane surface was imaged in a scan size of $2.0 \mu \mathrm{m} \times 2.0 \mu \mathrm{m}$ and the surface roughness was obtained by tapping mode.

The membrane hydrophobicity was exhibited by gauge of contact angle of droplet with the OCA20 Video-Based Contact Angle Meter (DataPhysics Instruments Ltd., Germany). Pure water droplet of about $0.5 \mu \mathrm{L}$ was carefully dropped onto the membrane surface through a syringe under ambient temperature and the contact angle was obtained by measuring five different positions.
The porosity $\varepsilon$ of flat-sheet membrane was determined by gravimetric method and calculated by the following equation [38]:

$\varepsilon=\frac{m_{1}-m_{2}}{\rho_{L} \cdot A \cdot l}$

where $m_{1}$ is the weight of the wet membrane, $m_{2}$ is the weight of the dry membrane, $\rho_{L}$ is the liquid density, $A$ is the effective area of the sample and $l$ is the membrane thickness. The liquid used for porosity measurement named Porefil was supported by IB-FT GmbH (Germany) and its surface tension and density were $16 \mathrm{dyn} / \mathrm{cm}$ and $1.87 \mathrm{~g} / \mathrm{mL}$, respectively.

The mean pore size and pore size distribution of the prepared membrane were investigated by using a capillary flow porometer (Porolux 1000, IB-FT GmbH, Germany). The membrane was fully wetted with the Porefil, then the measurement was carried out following the procedure described in literature [18]. The mean pore size and pore size distribution were determined with the aid of the computer software coupled to CFP.

\subsection{DCMD setup}

Experiments were carried out with the apparatus shown in Fig. 1. The membrane module was a plate and frame consisting of two chambers, one for the feed and the other for distillate. The prepared flat-sheet membrane was tightly clamped between the two chambers and had an effective area of $7.47 \times 10^{-3} \mathrm{~m}^{2}$. Both chambers had a thickness of $1.0 \mathrm{~mm}$ and there were 10 flow paths with the same width of $7.0 \mathrm{~mm}$ for each chamber. The feed and permeate flowed concurrently from the bottom to the upper part of the module with the help of two magnetic pumps (MP-215R, Shanghai Seisun Bumps, China), the fluid temperature was controlled by water baths and monitored at the inlet and outlet of the module using four Pt-100

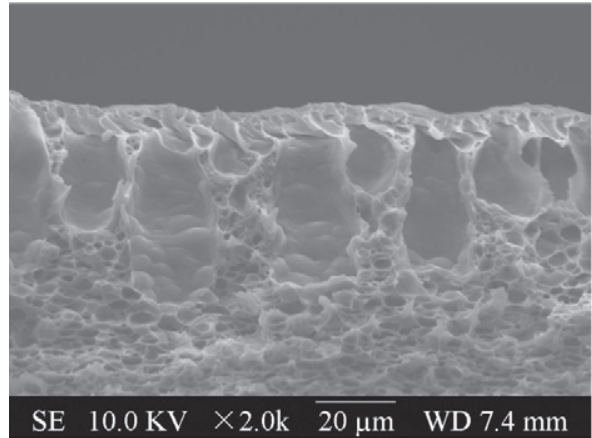

Cross section

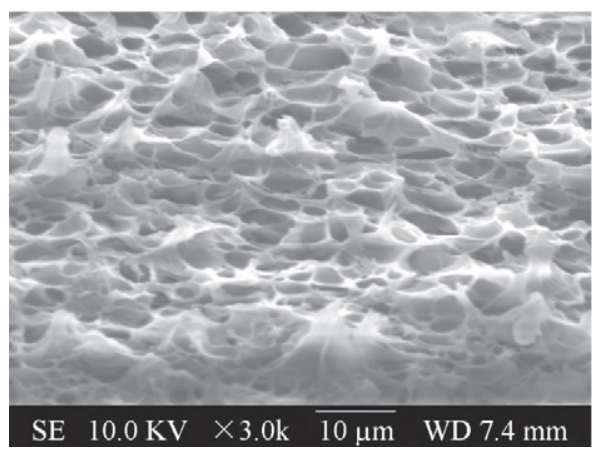

Sponge-like layer

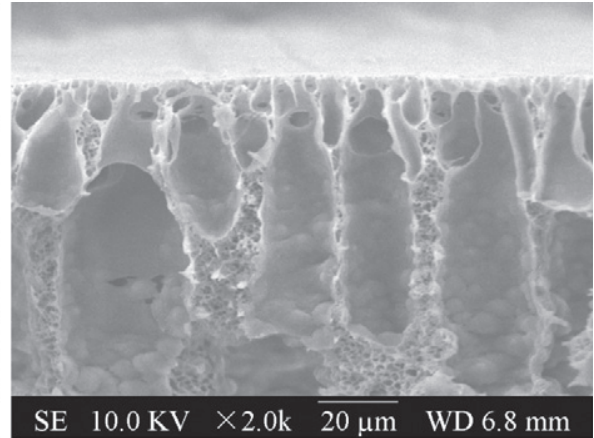

Cross section near membrane surface

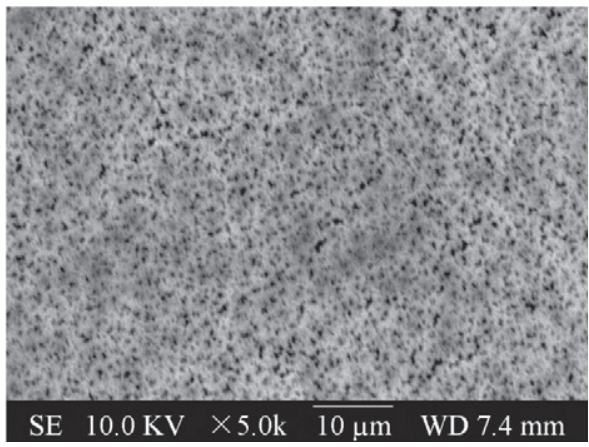

Membrane surface

Fig. 2. SEM morphology of the prepared PVDF flat-sheet membrane. 


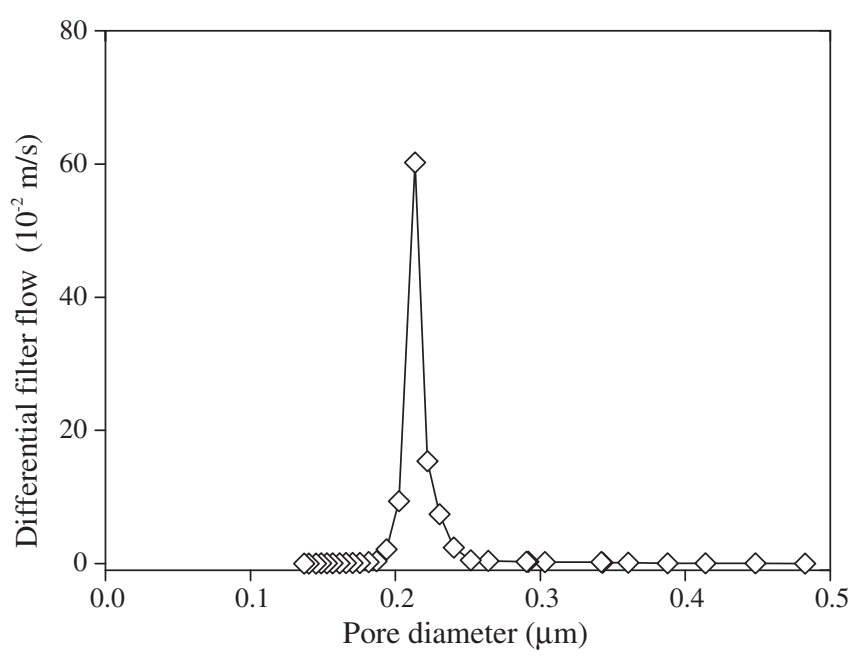

Fig. 3. Pore size distribution of the prepared flat-sheet membrane.

thermoresistances connected to a digital meter (Digit RTD, model XMT808 , Yuyao Changjiang Temperature Meter Instruments, China) with an accuracy of $\pm 0.1{ }^{\circ} \mathrm{C}$, and the circulation rate of the feed and permeate were adjusted by two rotameters (LZS-15, Yuyao Yinhuan Flowmeter, China).

\subsection{Analytical methods}

The concentrations of boron, silicon and cations such as $\mathrm{K}^{+}, \mathrm{Na}^{+}$, $\mathrm{Ca}^{2+}, \mathrm{Mg}^{2+}$ and $\mathrm{Sr}^{2+}$ in seawater sample were determined by ICPAES (Optima 2000DV, Perkin Elmer, USA). Anions such as F', $\mathrm{Cl}^{-}, \mathrm{Br}^{-}$ and $\mathrm{SO}_{4}^{2-}$ were determined by ion chromatography (861, Metrohm, Switzerland). Total organic carbon (TOC) and conductivity of the sample were determined by a TOC analyzer (8000, Phoenix, USA) and conductivity meter (CO150, HACH, USA), respectively. Alkalinity, carbonate and bicarbonate were measured using an alkalinity titration. The seawater sample was taken from the Yellow Sea (Shandong Province, China) and the chemical composition of the untreated seawater is shown in Table 1.

The concentration of boron in the permeate sample was determined by three time analyses using ICP-MS (7500a, Agilent, USA). The permeate conductivity was measured using an electric conductivity monitor (CM-230A, Shijiazhuang Create Instrumentation Technologies, China).

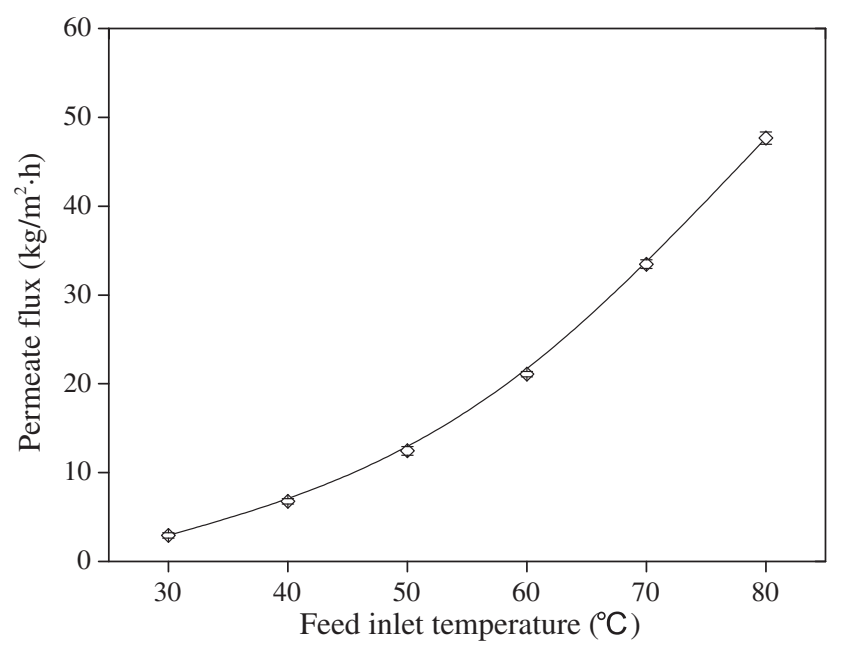

Fig. 5. Permeate flux of the prepared flat-sheet membrane as a function of feed temperature.

\subsection{Boron removal and desalination experiments}

The application of PVDF flat-sheet membrane for boron removal and desalination from seawater through DCMD was performed with the inlet temperatures of hot feed and cold permeate at $53{ }^{\circ} \mathrm{C}$ and $20^{\circ} \mathrm{C}$, respectively. The circulation rate of the feed and permeate were kept constant at $70 \mathrm{~L} / \mathrm{h}$ (about $0.28 \mathrm{~m} / \mathrm{s}$ ). During the boron removal and desalination process, the initial volume of feed was $5.0 \mathrm{~L}$ and there was no make-up water added into the feed tank, which meant that the feed was gradually concentrated. The boron concentration and conductivity of permeate were measured at different $\mathrm{CF}$ values to evaluate the flat-sheet membrane rejection. The concentration factor $K$ can be calculated by the following equation:

$K=\frac{Q_{0}}{Q_{o}-Q_{p}}$

where $Q_{o}$ is the initial quantity of feed $(\mathrm{kg})$, and $Q_{p}$ is the cumulative permeate production $(\mathrm{kg})$. The permeate flux $J$ was calculated by the following equation:

$J=\frac{\Delta W}{A \Delta t}$,

where $J$ is the permeate flux $\left(\mathrm{kg} / \mathrm{m}^{2} \mathrm{~h}\right), \Delta W$ is the quantity of distillate $(\mathrm{kg}), A$ is the effective area of flat-sheet membrane $\left(\mathrm{m}^{2}\right)$ and $\Delta t$ is the

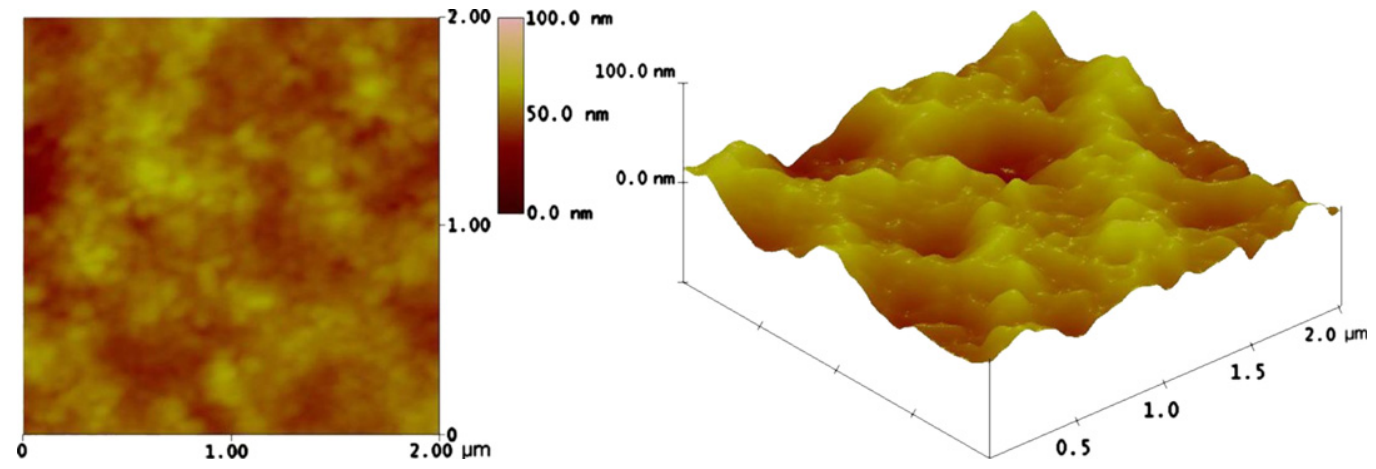

Surface topography

Three-dimensional image

Fig. 4. AFM images of the prepared flat-sheet membrane surface. 


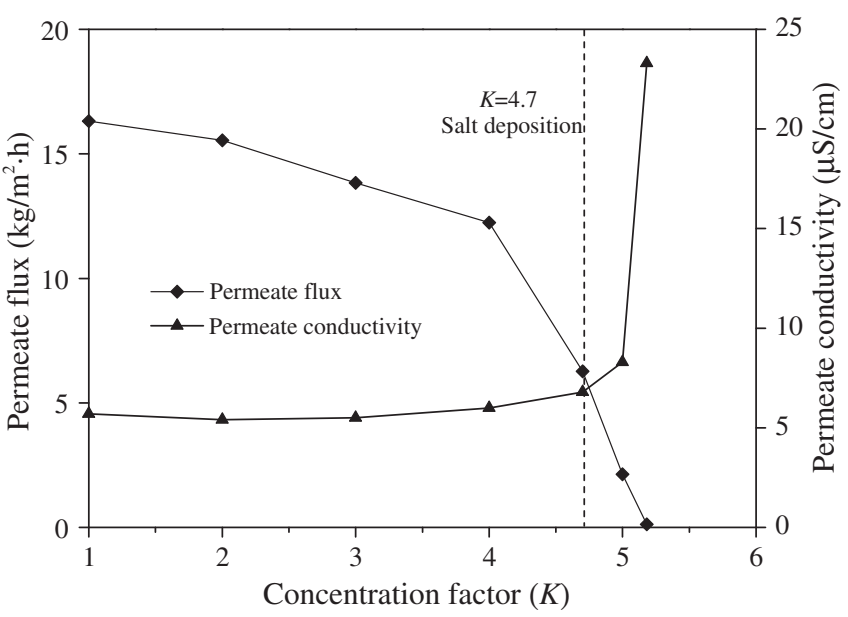

Fig. 6. Permeate flux and permeate conductivity as a function of the CF value.

sampling time (h). The rejection coefficient $R$ was calculated according to the following equation:

$R=\frac{C_{f}-C_{p}}{C_{f}}$,

where $C_{f}$ and $C_{p}$ are the concentration of the feed and permeate, respectively.

The formation of membrane scaling in seawater concentration process will cause the clogging of membrane pores and membrane pore wetting, which may decline the permeate flux and solute rejection. In order to eliminate the negative influence of membrane scaling, the antiscalant PAA was added into the feed solution. Batch boron removal and desalination experiments were carried out with PAA dosage in the range of $5-15 \mathrm{mg} / \mathrm{L}$. To evaluate the influence of PAA on mitigating the potential for membrane scaling, the boron concentration and conductivity of permeate were measured at different $\mathrm{CF}$ values, the SEM image of flat-sheet membrane after the DCMD process was investigated and the membrane surface was analyzed using energy dispersive X-ray spectroscopy (EDS) analysis system.

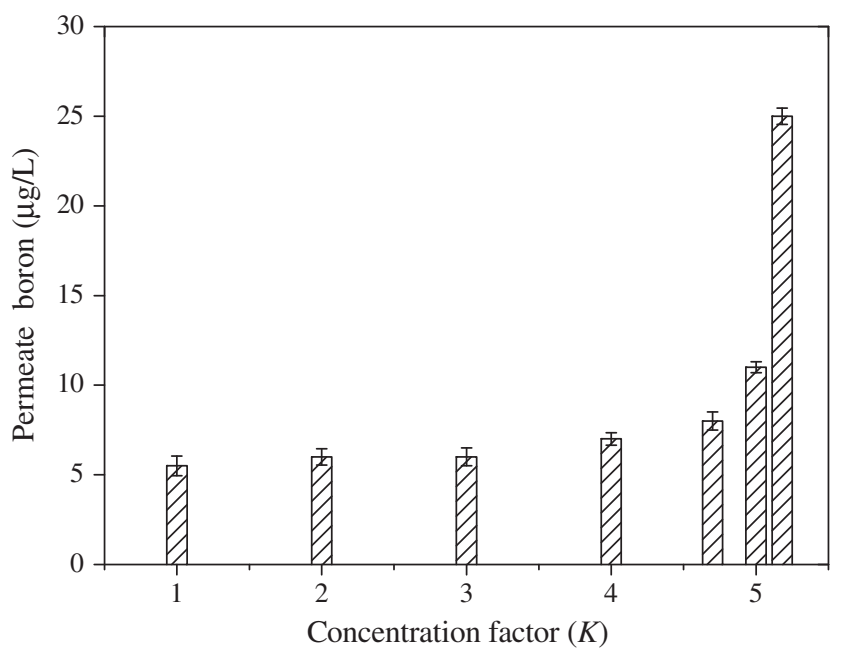

Fig. 7. The influence of $\mathrm{CF}$ value on permeate boron concentration.

\section{Results and discussions}

\subsection{Characterization of flat-sheet membrane}

\subsubsection{Membrane morphology analysis}

The morphology of the self-prepared PVDF flat-sheet membrane is shown in Fig. 2; it can be seen that the PVDF separation function layer was composed of top skin layer, finger-like macrovoids and sponge-like layer. The thickness of the PVDF separation function layer was about $35-45 \mu \mathrm{m}$ and the finger-like cavities made up about half the total volume of the separation function layer. On the whole, the self-prepared membrane had long finger-like cavities, loose spongy structure, porous and ultra-thin top skin, which may provide the membrane with less resistance for water vapor transporting and ensure the membrane with high permeate flux.

The thermodynamic homogeneity and stability of the dope solution got enhanced by the swelling action of the non-solvent additive acetone and this made the membrane exhibit good uniformity either on sponge-like layer or on membrane surface. $\mathrm{H}_{3} \mathrm{PO}_{4}$ possessed strong interactions with the polymer and solvent, the addition of it enhanced the PVDF polymer dope solution viscosity from $3.80 \mathrm{~Pa} \cdot \mathrm{s}$ (for PVDF/DMAc/acetone (20/75/5, wt.\%) dope) to $3.97 \mathrm{~Pa} \cdot \mathrm{s}$ (for PVDF/DMAc/acetone $/ \mathrm{H}_{3} \mathrm{PO}_{4}(20 / 72 / 5 / 3$, wt.\%) dope) at a dope solution temperature of $50{ }^{\circ} \mathrm{C}$. The strong interactions among the components of the dope tended to delay the phase separation rate, so the sponge-like structures became porous and loose. In addition, during the flat-sheet membrane preparation, ultrapure water was applied as the coagulant to induce immediate phase inversion and form the porous and ultra-thin top skin.

\subsubsection{Porosity, pore size and pore size distribution}

The pore size distribution of the flat-sheet membrane is presented in Fig. 3. It can be clearly seen that the effective pores show a very narrow distribution mainly from 0.20 to $0.25 \mu \mathrm{m}$; this kind of membrane pore size distribution may minimize the water leakage through the membrane. The mean pore size of the membrane was about $0.22 \mu \mathrm{m}$ and the maximum diameter of the membrane pores was $0.48 \mu \mathrm{m}$ from bubble point data. The liquid entry pressure of water (LEPw) is about 6.0 bar for the membrane according to the method described by Smolders and Franken [39]. The whole porosity of the PVDF flat-sheet membrane was $55.8 \%$, which was in agreement with the analysis of membrane morphology and also verified that the mixture of acetone and $\mathrm{H}_{3} \mathrm{PO}_{4}$ as non-solvent additive was beneficial to obtain a flatsheet membrane with high porosity.

\subsubsection{Membrane surface analysis}

The AFM images of the prepared flat-sheet membrane can be observed in Fig. 4. Roughness parameters were obtained with the AFM analysis software, and the values of the average roughness $\left(R_{a}\right)$, the root mean square roughness $\left(R_{q}\right)$ and the maximum roughness $\left(R_{\max }\right)$ were $13.37 \mathrm{~nm}, 15.79 \mathrm{~nm}$ and $105.86 \mathrm{~nm}$, respectively. In general, $R_{a}$ and $R_{q}$ seem to be the most helpful and consistent to characterize surface topography of the membrane, $R_{\max }$ can be affected by local imperfections or sample contamination leading to higher value than expected and membrane surface characterization based on the $R_{\max }$ could be unreliable. The mean nodule size of the membrane surface was about $60.51 \mathrm{~nm}$ calculated with the aid of the computer software coupled to AFM.

The membrane hydrophilic/hydrophobic property can be characterized by contact angle, which is related to membrane surface roughness, nodule size, porosity and pore diameter except for membrane surface composition [40]. The contact angle of the flat-sheet membrane was about $82.6 \pm 0.7^{\circ}$; it demonstrated that the separation function layer surface was hydrophobic and the flat-sheet membrane can be used in MD process. 

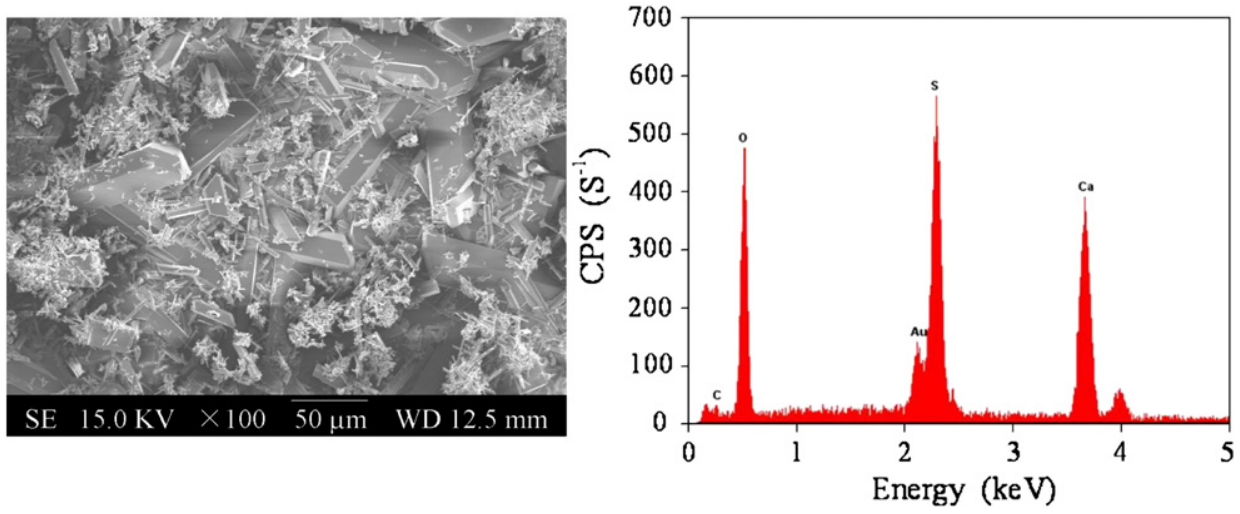

Fig. 8. SEM image and microanalysis report of the scale deposits on membrane surface.

\subsubsection{Membrane permeability test}

The permeability of the flat-sheet membrane was tested through the DCMD process. During the experiment, the $\mathrm{NaCl}$ concentration in the hot feed solution was kept constant at $35 \mathrm{~g} / \mathrm{L}$. The feed temperature at the inlet of membrane module, $T_{\text {f-inlet }}$, is adjusted from 30 to $80^{\circ} \mathrm{C}$, and the inlet temperature of the cold distillate, $T_{p \text {-inlet, }}$ is kept constant at $20^{\circ} \mathrm{C}$. The membrane permeate flux is shown in Fig. 5. The maximum permeate flux about $47.6 \mathrm{~kg} / \mathrm{m}^{2} \mathrm{~h}$ was achieved for the prepared flatsheet membrane with the inlet temperature of hot feed at about $80.5{ }^{\circ} \mathrm{C}$. In the membrane permeability test process, the conductivity of the cold permeate under different hot feed temperatures was less than $8.0 \mu \mathrm{S} / \mathrm{cm}$, which indicated that the salt rejection achieved $99.9 \%$ for the flat-sheet membrane.

\subsection{Boron removal and desalination}

\subsubsection{Effect of CF value}

The influence of CF value on the permeate flux and permeate conductivity is presented in Fig. 6 . As can be seen, the $\mathrm{CF}$ value had a marked influence on the DCMD performance. With the increase of the $\mathrm{CF}$ value, the permeate flux decreased gradually before the $\mathrm{CF}$ value reached 4.0 , then the permeate flux dropped sharply. When the CF value got close to 5.2 , the permeate flux approached zero and the permeate conductivity increased to $23 \mu \mathrm{S} / \mathrm{cm}$. The variation of permeate boron with the CF value is shown in Fig. 7. In the CF range of 1.0 to 4.0, the permeate boron concentration was below $10 \mu \mathrm{g} / \mathrm{L}$. Although the permeate boron increased rapidly after the $\mathrm{CF}$ value reached 4.0 , the boron rejection can still keep higher than $99.9 \%$ and the permeate boron concentration was far lower than the limit value for boron in drinking water.

The variation of the permeate quality and flux with CF value was mainly due to the salt concentration increase and the formation of deposit in the boron removal and desalination process of seawater. Heating the feed caused a shift from bicarbonate ion to carbonate ion and scale deposits would form from the salts whose solubility is generally limited because of their concentration being increased with the $\mathrm{CF}$ value increase. The concentrated seawater in feed tank became turbid when the $C F$ value reached 4.7 , which meant that there was scale precipitated out. The scales polluted the membrane surface and the membrane pores would be partly clogged and wetted, so both the permeate quality and flux declined rapidly.

When the DCMD experiment ended, it was found that the membrane surface was covered with pasty scales and the SEM image of the scale deposits is presented in Fig. 8. As can be seen, the scales consist mainly of needle-shaped crystals. The SEM-EDS analysis revealed that the needle-shaped crystal was calcium sulphate and the scale deposits also contained a small amount of calcium carbonate.
The experimental results showed that the scale deposits formed during the concentration process was the major factor which aggravated the flat-sheet membrane performance. To obtain higher water recovery, it was necessary to add an antiscalant into the feed to mitigate the potential for membrane scaling.

\subsubsection{Performance stability investigation}

To investigate the separation performance stability of the flat-sheet membrane, a $300 \mathrm{~h}$ continuous boron removal and desalination experiment was conducted with the feed solution at $53{ }^{\circ} \mathrm{C}$ and the cold distillate water at $20^{\circ} \mathrm{C}$. During this process, the $\mathrm{CF}$ value was kept constant at 4.0 , which meant that the water recovery reached about $75 \%$. To keep the CF value constant, the obtained permeate was reflowed to the feed tank every $1 \mathrm{~h}$. The other operating parameters were in accordance with the seawater concentration process.

The variation of permeate flux and permeate conductivity with operating time is presented in Fig. 9. It can be seen that the permeate flux maintains about $12.0-12.3 \mathrm{~kg} / \mathrm{m}^{2} \mathrm{~h}$ during the experiment and there are no obvious changes of permeate flux. The permeate conductivity stabilized at about $5.0-7.5 \mu \mathrm{S} / \mathrm{cm}$ and all the permeate boron were below $10 \mu \mathrm{g} / \mathrm{L}$ as shown in Fig. 10. All the experimental results demonstrated that the self-prepared flat-sheet membrane had stable permeability and solute rejection; the DCMD process was extremely efficient for boron removal and desalination from seawater.

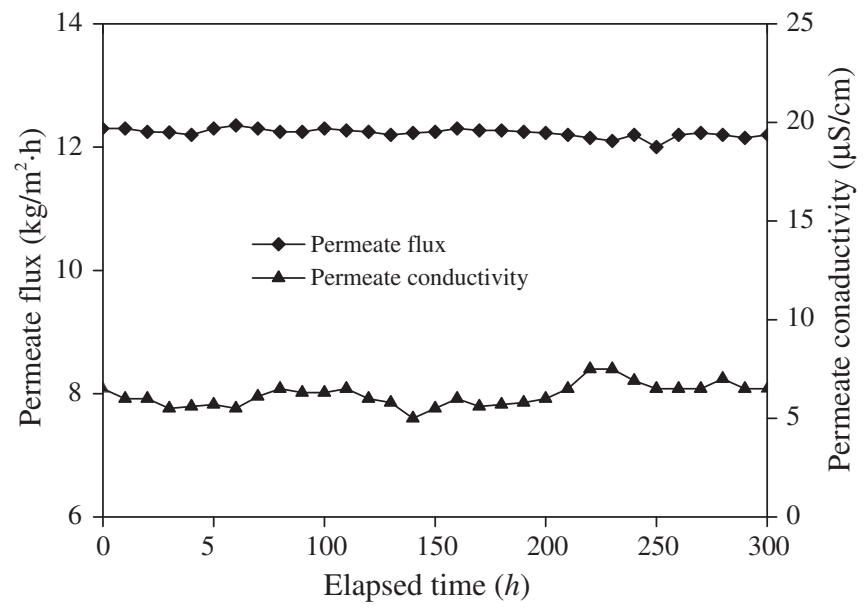

Fig. 9. Variation of permeate flux and permeate conductivity during continuous $300 \mathrm{~h}$ DCMD process. 


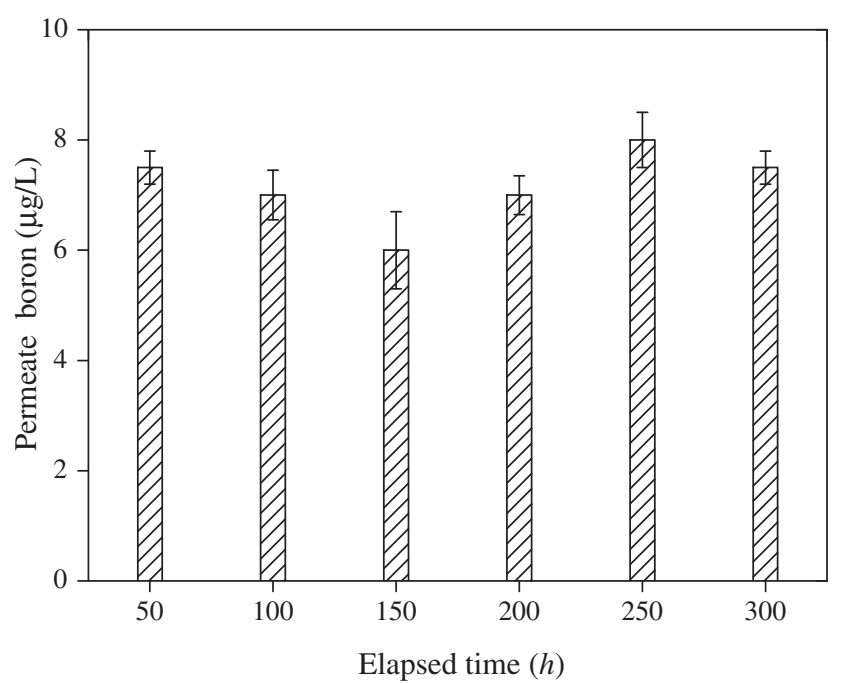

Fig. 10. Variation of permeate boron concentration during continuous $300 \mathrm{~h}$ DCMD process.

\subsection{Effect of antiscalant polyacrylic acid}

\subsubsection{Effect of polyacrylic acid dosage}

One of the available methods for scale deposition control in seawater concentration process involves the addition of an antiscalant to the feed. It has been reported that the polyelectrolyte containing carboxyl groups are particularly effective as hydrated calcium sulphate crystal growth inhibitors [41-43]. The antiscalant can cause a reduction in the amount of solids deposited from the solution and decrease the rate of deposition by interfering with nucleation and crystal growth of the precipitate and with the particle-particle interactions in the precipitate suspension.

Polyacrylic acid (PAA) antiscalant belongs to the polycarboxylate type; it is nontoxic and soluble in water. As an effective calcium sulphate scale inhibitor, PAA was selected as the antiscalant added into the feed seawater in this investigation with the dosage of $5 \mathrm{mg} / \mathrm{L}, 10 \mathrm{mg} / \mathrm{L}$ and $15 \mathrm{mg} / \mathrm{L}$, respectively. The variation of permeate flux and permeate conductivity with CF value is shown in Fig. 11. It can be seen that although the permeate flux decreased with $C F$ value increase, the addition of PAA effectively delayed the formation of deposit. Compared

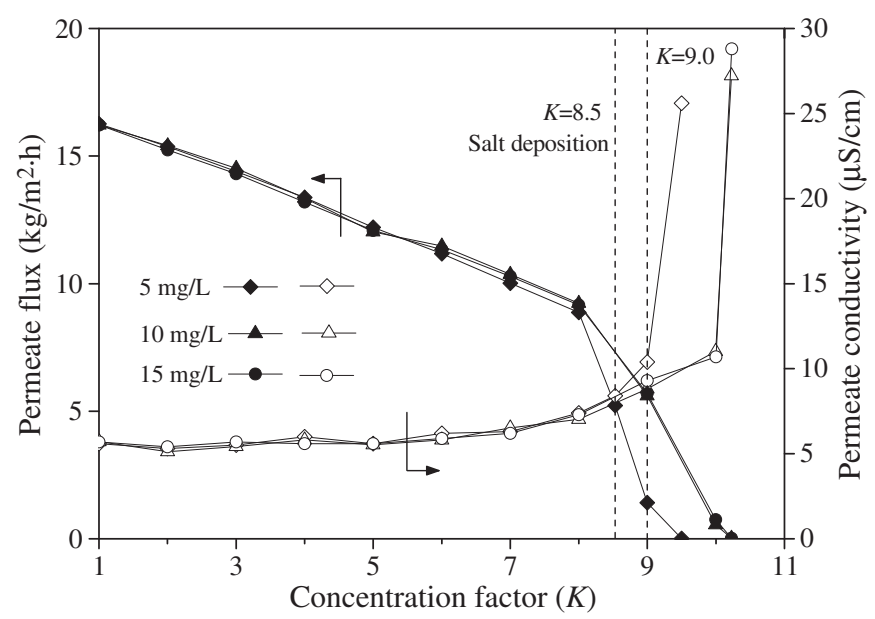

Fig. 11. Permeate flux and permeate conductivity as a function of the $C F$ value with different PAA addition.

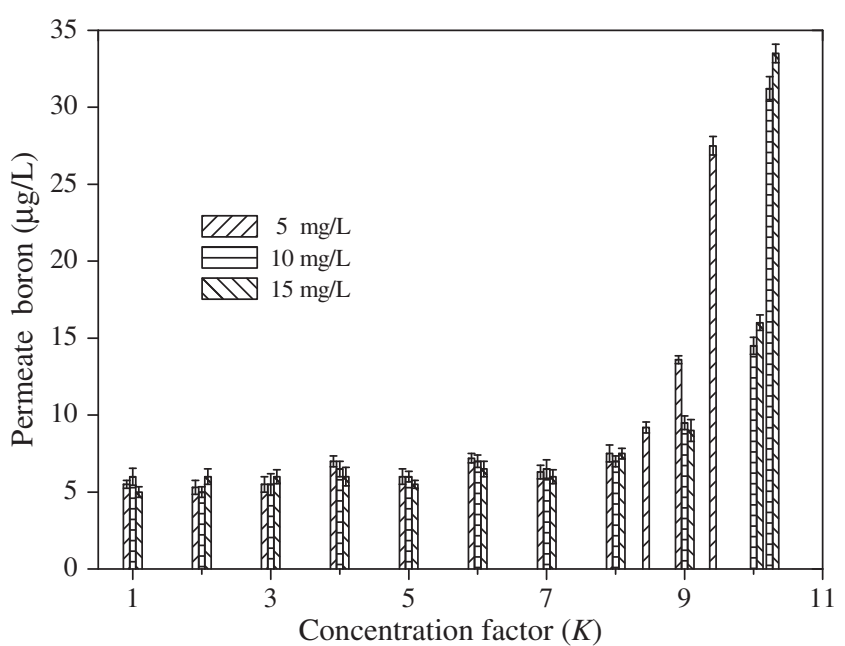

Fig. 12. The influence of $\mathrm{CF}$ value on permeate boron concentration with different PAA addition.

with the experiment without antiscalant addition, the permeate flux approached zero until the $\mathrm{CF}$ value exceeded 9.0. The permeate boron concentration was less than $15 \mu \mathrm{g} / \mathrm{L}$ before the CF value reached 9.0 as shown in Fig. 12 and the permeate conductivity was below $10 \mu \mathrm{S} / \mathrm{cm}$.

The experimental results also showed that the dosage of antiscalant had considerable influence on DCMD process performance. For example, the concentrated seawater in feed tank became turbid when the $\mathrm{CF}$ value reached 8.5 and the permeate flux approached zero when the $\mathrm{CF}$ value got to 9.5 with the dosage of PAA at $5 \mathrm{mg} / \mathrm{L}$. When the dosage of PAA increased to $10 \mathrm{mg} / \mathrm{L}$, the $\mathrm{CF}$ values at which the concentrated seawater became turbid and the permeate flux declined to zero were extended to 9.0 and 10.3, respectively. In Fig. 11, it can be found that the addition of $10 \mathrm{mg} / \mathrm{L}$ PAA was advisable, and the DCMD performance with a higher dosage of $15 \mathrm{mg} / \mathrm{L}$ PAA was similar to that with $10 \mathrm{mg} / \mathrm{L}$ addition. Further, although the addition of PAA could effectively delay the formation of deposit, it did not mean that the seawater could be condensed without limit. When the experiments ended, it was found that the scale deposit covered membrane surface exhibited different morphologies with different antiscalant addition, as shown in Fig. 13, and the composition of elements in deposit was listed in Table 2.

During DCMD process with different antiscalant addition, the boron retention rate kept above $99 \%$ before the concentrated seawater became turbid and the permeate conductivity was no more than $10 \mu \mathrm{S} / \mathrm{cm}$, which indicated that the PAA addition would not destroy the prepared membrane hydrophobicity and solute retention capacity.

\subsubsection{Performance stability investigation}

A batch of $300 \mathrm{~h}$ continuous boron removal and desalination from seawater experiments was conducted to investigate the influence of $\mathrm{CF}$ value on separation performance stability of the flat-sheet membrane with the hot feed at $53{ }^{\circ} \mathrm{C}$ and the cold distillate at $20^{\circ} \mathrm{C}$. For all the experiments under different $\mathrm{CF}$ values, the dosage of PAA was kept at $10 \mathrm{mg} / \mathrm{L}$. As described before, the obtained permeate was reflowed to the feed tank during the DCMD experiment to keep the CF value constant and the other operating parameters were in accordance with the seawater concentration process.

The variation of permeate flux with operating time is presented in Fig. 14. It can be found that the permeate flux maintains about 11.2$11.5 \mathrm{~kg} / \mathrm{m}^{2} \mathrm{~h}$ and $10.2-10.4 \mathrm{~kg} / \mathrm{m}^{2} \mathrm{~h}$ with CF value kept constant at 6.0 and 7.0, respectively, and the permeate boron concentration remained stable in the range of $6.0 \mu \mathrm{g} / \mathrm{L}$ to $9.0 \mu \mathrm{g} / \mathrm{L}$. But when the CF value increased to 8.0 , the permeate flux would decline from initially 

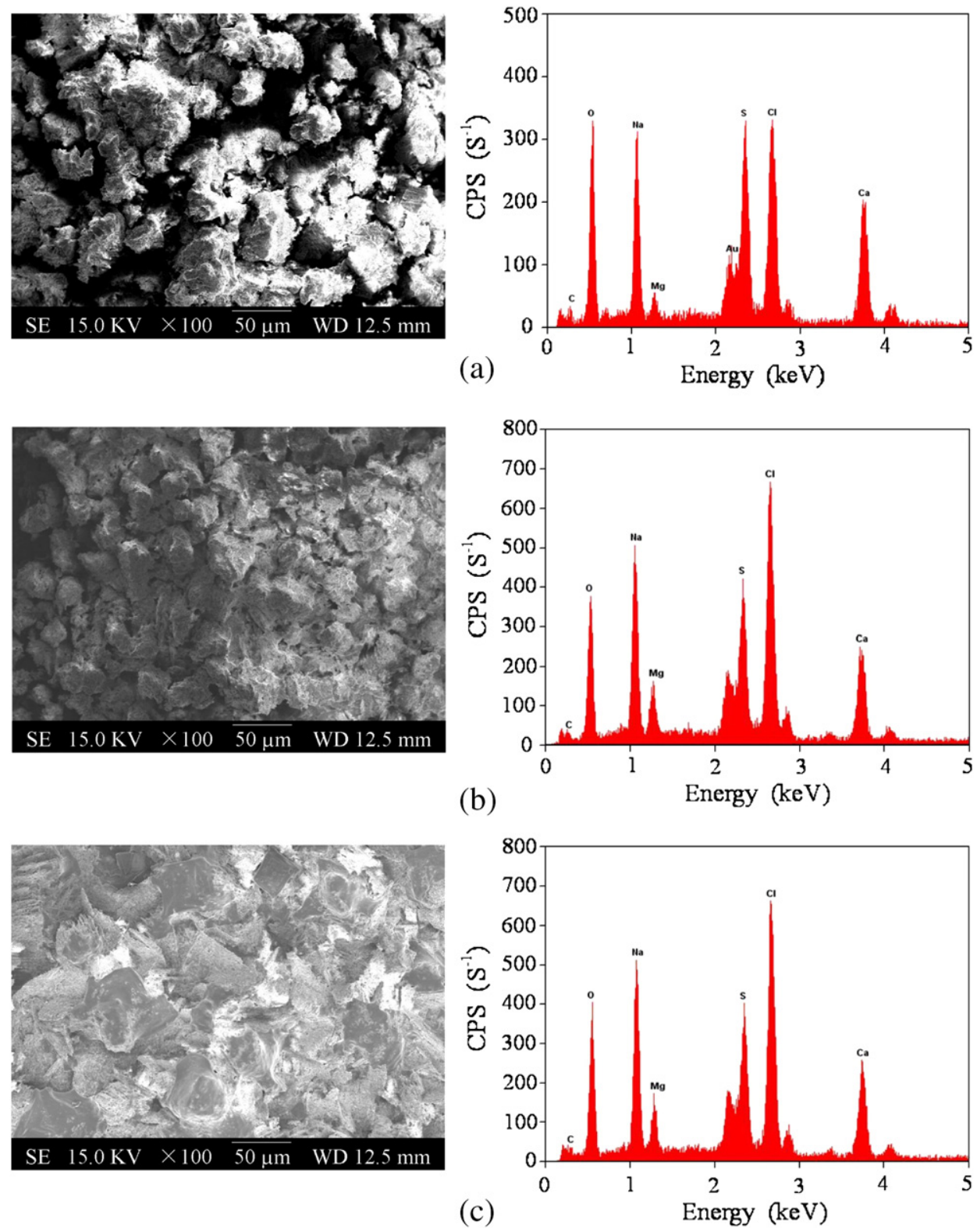

Fig. 13. SEM image and microanalysis report of the scale deposits on membrane surface with different PAA addition.

$9.3 \mathrm{~kg} / \mathrm{m}^{2} \mathrm{~h}$ to $7.2 \mathrm{~kg} / \mathrm{m}^{2}$ when the experiment was halted after $300 \mathrm{~h}$, which meant that the permeate flux decreased about $23 \%$. The permeate boron concentration increased from $7.0 \mu \mathrm{g} / \mathrm{L}$ to $335 \mu \mathrm{g} / \mathrm{L}$ as shown in Fig. 15, which indicated that the CF value of 8.0 was not suitable for DCMD boron removal because too higher $\mathrm{CF}$ value would introduce

Table 2

Composition of elements in deposit accumulated on the membrane surface.

\begin{tabular}{llll}
\hline \multirow{2}{*}{ Element } & wt.\% & & \\
\cline { 2 - 4 } & $\rho(\mathrm{PAA})=5 \mathrm{mg} / \mathrm{L}$ & $\rho(\mathrm{PAA})=10 \mathrm{mg} / \mathrm{L}$ & $\rho(\mathrm{PAA})=15 \mathrm{mg} / \mathrm{L}$ \\
\hline $\mathrm{Ca}$ & 17.79 & 15.76 & 13.27 \\
$\mathrm{~S}$ & 14.54 & 12.15 & 10.84 \\
$\mathrm{O}$ & 27.84 & 28.07 & 26.05 \\
$\mathrm{C}$ & 10.31 & 8.16 & 9.03 \\
$\mathrm{Na}$ & 10.26 & 14.91 & 14.64 \\
$\mathrm{Cl}$ & 17.71 & 20.54 & 25.32 \\
$\mathrm{Mg}$ & 1.55 & 0.41 & 0.85 \\
\hline
\end{tabular}

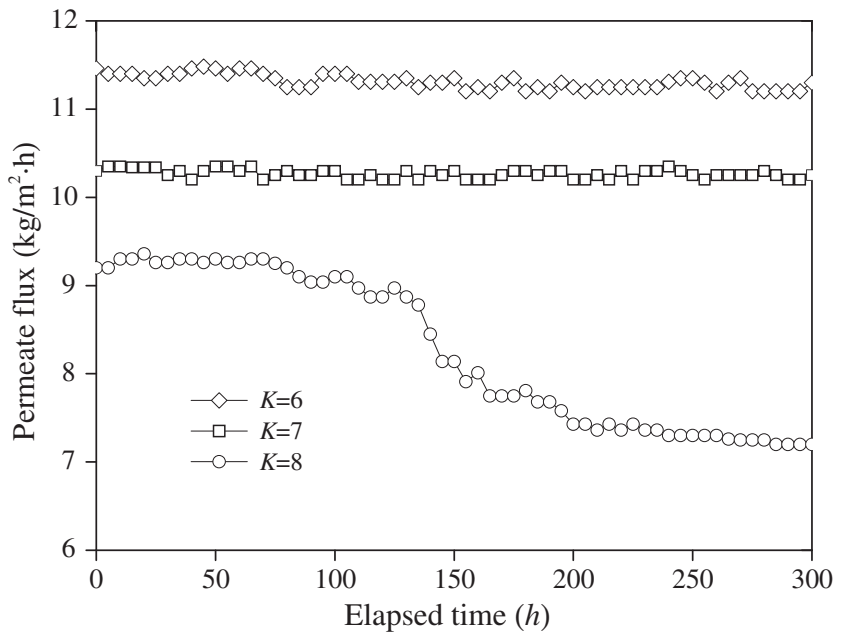

Fig. 14. Variation of permeate flux during continuous $300 \mathrm{~h} \mathrm{DCMD}$ process. 


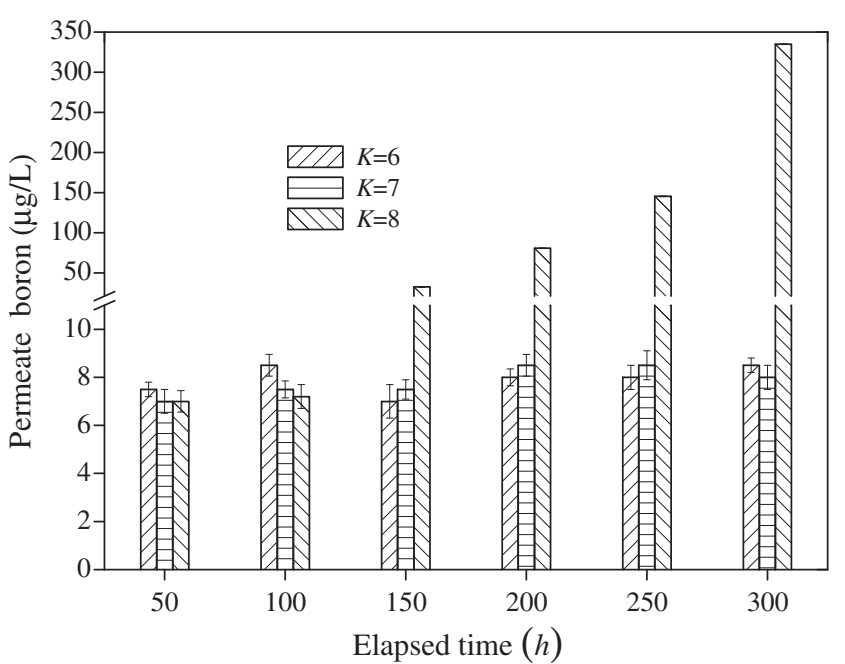

Fig. 15. Variation of permeate boron concentration during continuous $300 \mathrm{~h}$ DCMD process.

salt concentration increase and deposit formation. When the experiment with CF value kept constant at 8.0 was halted after $300 \mathrm{~h}$, it can be seen that there were small amounts of scale deposits on the membrane surface as shown in Fig. 16; the SEM-EDS analysis revealed that the deposits comprised mainly of calcium sulphate.

The experimental results demonstrated that the $\mathrm{CF}$ value of 7.0 was optimal for boron removal and desalination from seawater with the PAA dosage of $10 \mathrm{mg} / \mathrm{L}$. In addition, no scale deposit was found on the membrane surface when the experiment ended and the permeate conductivity stabilized at about $5.0-8.5 \mu \mathrm{S} / \mathrm{cm}$ for the experiments with CF values at 6.0 and 7.0.

\section{Conclusions}

In the present work, the application of DCMD for boron removal and desalination from seawater with self-prepared PVDF flat-sheet membrane was investigated systematically and the following conclusions were obtained:

(1) The self-prepared PVDF flat-sheet membrane had an ultra-thin top skin and a porous network sponge-like layer and its mean pore size was $0.22 \mu \mathrm{m}$ in diameter. The membrane also exhibited good hydrophobicity and its contact angle was about $82.6 \pm$ $0.7^{\circ}$. During DCMD test of $35 \mathrm{~g} / \mathrm{L}$ sodium chloride solution, the maximum permeate flux can achieve $47.6 \mathrm{~kg} / \mathrm{m}^{2} \mathrm{~h}$ with feed solution at $80.5^{\circ} \mathrm{C}$.

(2) The natural seawater containing $4.65 \mathrm{mg} / \mathrm{L}$ boron was treated by DCMD process for simultaneous boron removal and desalination. Although the permeate flux decreased with CF value increase, the permeate boron kept below $20 \mu \mathrm{g} / \mathrm{L}$ and the salt rejection was over $99.9 \%$. When the CF value exceeded 4.0 , there would be scale deposits formed because of the limited solubility. The scales polluted the membrane surface and membrane pores would be partly clogged and wetted, which induced the permeate quality and permeate flux rapid decline.

(3) The addition of antiscalant PAA could delay the formation of deposits and would not destroy the prepared membrane hydrophobicity and solute retention capacity. Through batch DCMD experiments, it was found that the optimal PAA dosage was $10 \mathrm{mg} / \mathrm{L}$ and the $\mathrm{CF}$ value of 7.0 was advisable. The membrane showed satisfying performance stability in $300 \mathrm{~h}$ continuous DCMD experiment, indicating that the prepared PVDF flat-sheet membrane and DCMD process may be of great potential to be utilized in boron removal and desalination from seawater.

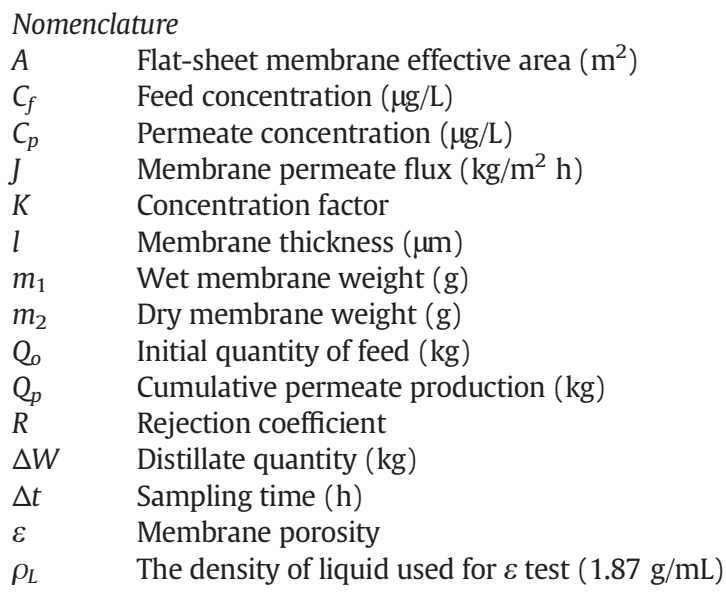

\section{Acknowledgments}

Financial support provided by the National Natural Science Foundation of China (nos. 51138008 and 51108445) and the special fund from the State Key Laboratory of Environmental Aquatic Chemistry (no. 13Z04ESPCT) are gratefully acknowledged.
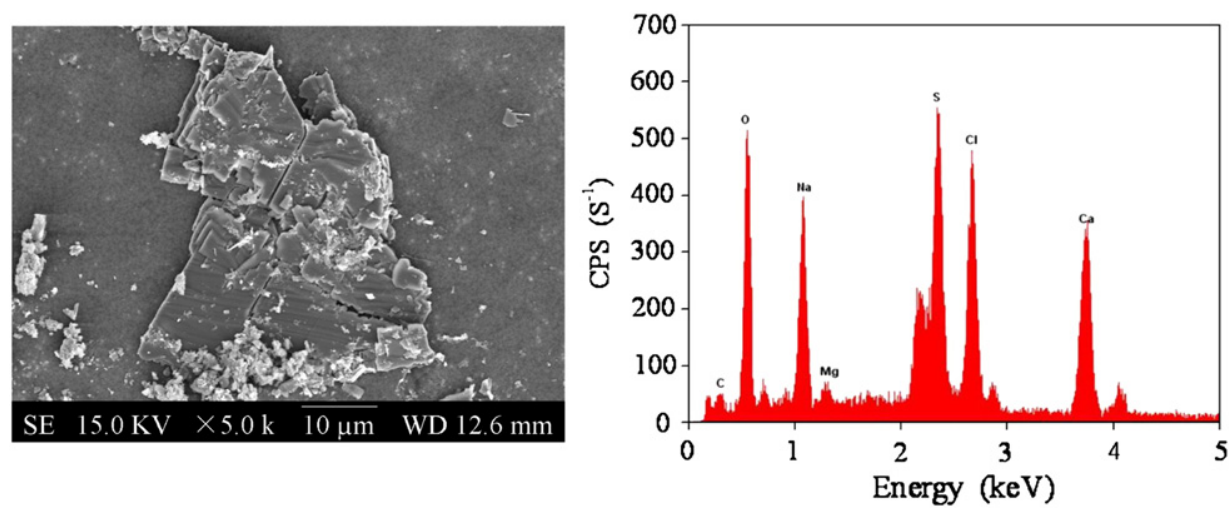

Fig. 16. SEM image and microanalysis report of the scale deposits on membrane surface with $10 \mathrm{mg} / \mathrm{L}$ PAA addition and CF value of 8.0. 


\section{References}

[1] Y.L. Xu, J.Q. Jiang, Technologies for boron removal, Ind. Eng. Chem. Res. 47 (2008) $16-24$.

[2] J.L. Parks, M. Edwards, Boron in the environment, Crit. Rev. Environ. Sci. Technol. 35 (2005) 81-114.

[3] L. Melnyk, V. Goncharuk, I. Butnyk, E. Tsapiuk, Boron removal from natural and wastewaters using combined sorption/membrane process, Desalination 185 (2005) 147-157.

[4] G.W. Sofw, Influence of boron to the organism communities of the system sewage treatment plant-receiving waters (model investigations), J. Eng. Vers. Int. Trade J. 126 (2000) 17-24.

[5] E.M. Shwarts, Are boron compounds useful or harmful? J. Chem. Interest Stable Prog. 2 (1994) 501-505.

[6] A.T. Philipenko, V.D. Grebenyk, L.A. Melnik, Extraction of boron compounds from natural and industrial waters, Khim. Tekhnol. Vody 12 (1990) 195-210.

[7] WHO, Guidelines for Drinking-Water Quality, 4th ed. World Health Organization, Geneva, Switzerland, 2011.

[8] Y.T. Wei, Y.M. Zheng, J.P. Chen, Design and fabrication of an innovative and environmental friendly adsorbent for boron removal, Water Res. 45 (2011) 2297-2305.

[9] K. Rahmawati, N. Ghaffour, C. Aubry, G.L. Amy, Boron removal efficiency from Red Sea water using different SWRO/BWRO membranes, J. Membr. Sci. 423-424 (2012) 522-529.

[10] N. Öztürk, D. Kavak, T.E. Köse, Boron removal from aqueous solution by reverse osmosis, Desalination 223 (2008) 1-9.

[11] Z.C. Çelik, B.Z. Cana, M.M. Kocakerim, Boron removal from aqueous solutions by activated carbon impregnated with salicylic acid, J. Hazard. Mater. 152 (2008) 415-422.

[12] D.Y. Hou, J. Wang, X.C. Sun, Z.K. Luan, C.W. Zhao, X.J. Ren, Boron removal from aqueous solution by direct contact membrane distillation, J. Hazard. Mater. 177 (2010) 613-619.

[13] C. Jacob, Seawater desalination: boron removal by ion exchange technology, Desalination 205 (2007) 47-52.

[14] M.O. Simonnot, C. Castel, M. Nicolaï, C. Rosin, M. Sardin, H. Jauffret, Boron removal from drinking water with a boron selective resin: is the treatment really selective? Water Res. 34 (2000) 109-116.

[15] A. Bick, G. Oron, Post-treatment design of seawater reverse osmosis plants: boron removal technology selection for potable water production and environmental control, Desalination 178 (2005) 233-246.

[16] N. Hilal, G.J. Kim, C. Somerfield, Boron removal from saline water: a comprehensive review, Desalination 273 (2011) 23-35.

[17] P. Glueckstern, M. Priel, Optimization of boron removal in old and new SWRO systems, Desalination 156 (2003) 219-228.

[18] K.Y. Wang, T.S. Chung, M. Grata, Hydrophobic PVDF hollow fiber membranes with narrow pore size distribution and ultra-thin skin for the fresh water production through membrane distillation, Chem. Eng. Sci. 63 (2008) 2587-2589.

[19] K.W. Lawson, D.R. Lloyd, Membrane distillation, J. Membr. Sci. 124 (1997) 1-25.

[20] E. El-Zanati, K.M. El-Khatib, Integrated membrane-based desalination system, Desalination 205 (2007) 15-25.

[21] J.H. Hanemaaijer, J.V. Medevoort, A.E. Jansen, C. Dotremont, E.V. Sonsbeek, T. Yuan, L.D. Ryck, Memstill membrane distillation-a future desalination technology, Desalination 199 (2006) 175-176.

[22] L. Martínez-Díez, F.J. Florido-Díaz, Desalination of brines by membrane distillation, Desalination 137 (2001) 267-273.
[23] M.S.H. Bader, A hybrid liquid-phase precipitation (LPP) process in conjunction with membrane distillation (MD) for the treatment of the INEEL sodium-bearing liquid waste, J. Hazard. Mater. 121 (2005) 89-108.

[24] K. Bélafi-Bakó, B. Koroknai, Enhanced water flux in fruit juice concentration: coupled operation of osmotic evaporation and membrane distillation, J. Membr. Sci. 269 (2006) 187-193.

[25] M. Tomaszewska, Concentration and purification of fluosilicic acid by membrane distillation, Ind. Eng. Chem. Res. 39 (2000) 3038-3041.

[26] M. Gryta, K. Karakulski, The application of membrane distillation for the concentration of oil-water emulsions, Desalination 121 (1999) 23-29.

[27] T.G. Zakrzewska, M. Harasimowicz, A.G. Chmielewski, Membrane processes in nuclear technology-application for liquid radioactive waste treatment, Sep. Purif. Technol. 22 (2001) 617-625.

[28] A. Cipollina, M.G. Di Sparti, A. Tamburini, G. Micale, Development of a membrane distillation module for solar energy seawater desalination, Chem. Eng. Res. Des. 90 (2012) 2101-2121.

[29] F. He, J. Gilron, K.K. Sirkar, High water recovery in direct contact membrane distillation using a series of cascades, Desalination 323 (2013) 48-54.

[30] C. Cabassud, D. Wirth, Membrane distillation for water desalination: how to choose an appropriate membrane? Desalination 157 (2003) 307-314.

[31] S.T. Hsu, K.T. Cheng, J.S. Chiou, Seawater desalination by direct contact membrane distillation, Desalination 143 (2002) 279-287.

[32] E. Curcio, X.S. Ji, G.D. Profio, A.O. Sulaiman, E. Fontananova, E. Drioli, Membrane distillation operated at high seawater concentration factors: role of the membrane on $\mathrm{CaCO}_{3}$ scaling in presence of humic acid, J. Membr. Sci. 346 (2010) 263-269.

[33] X.S. Ji, E. Curcio, S.A. Obaidani, G.D. Profio, E. Fontananova, E. Drioli, Membrane distillation-crystallization of seawater reverse osmosis brines, Sep. Purif. Technol. 71 (2010) 76-82.

[34] J.P. Mericq, S. Laborie, C. Cabassud, Evaluation of systems coupling vacuum membrane distillation and solar energy for seawater desalination, Chem. Eng. J. 166 (2011) 596-606

[35] S. Al-Obaidani, E. Curcio, F. Macedonio, G. Di Profio, H. Al-Hinai, E. Drioli, Potential of membrane distillation in seawater desalination: thermal efficiency, sensitivity study and cost estimation, J. Membr. Sci. 323 (2008) 85-98.

[36] V. Calabro, E. Drioli, Polarization phenomena in integrated reverse osmosis and membrane distillation for seawater desalination and waste water treatment, Desalination 108 (1996) 81-82.

[37] L. Martinez, F.J. Florido-Díaz, Theoretical and experimental studies on desalination using membrane distillation, Desalination 139 (2001) 373-379.

[38] J.L. Wang, L. Wang, W.X. Ruan, C. Zhang, J.B. Ji, Rheology behavior of high-density polyethylene/diluent blends and fabrication of hollow-fiber membranes via thermally induced phase separation, J. Appl. Polym. Sci. 118 (2010) 2186-2194.

[39] K. Smolders, A.C.M. Franken, Terminology for membrane distillation, Desalination 72 (1989) 249-262.

[40] S. Rajesh, K.H. Shobana, S. Anitharaj, D.R. Mohan, Preparation, morphology, performance, and hydrophilicity studies of poly(amide-imide) incorporated cellulose acetate ultrafiltration membranes, Ind. Eng. Chem. Res. 50 (2011) 5550-5564.

[41] M.P.C. Weijnen, G.M. van Rosmalen, The influence of various polyelectrolytes on the precipitation of gypsum, Desalination 54 (1985) 239-261.

[42] Z. Amjad, Applications of antiscalants to control calcium sulfate scaling in reverse osmosis systems, Desalination 54 (1985) 263-276.

[43] F. He, K.K. Sirkar, J. Gilron, Effects of antiscalants to mitigate membrane scaling by direct contact membrane distillation, J. Membr. Sci. 345 (2009) 53-58. 